\title{
Potential health impacts of multiple drug prescribing for older people: a case-control study
}

Umesh T Kadam

\begin{abstract}
Using a prescription-survey linkage dataset for 4506 people aged $\geq 50$ years from six general practices, the null hypothesis that multiple drug prescribing was not associated with changes in health over a 3-year time-period was investigated. There was a significant trend in the adjusted association between higher levels of multidrug therapy and deterioration in both physical and psychological health over a 3-year time period. The study highlights the potential need for assessing drug prescribing in terms of overall health.

Keywords

comorbidity; drug utilisation review; polypharmacy; quality of life.
\end{abstract}

\section{INTRODUCTION}

One of the key interventions in reduction of disease risk and progression are drug therapies. Polypharmacy in general practice is high, ${ }^{1}$ especially in older populations, and routine drug use has been further formalised by chronic disease management approaches. These changes have been part of the larger public health initiative aimed at the reduction of disease-specific complications and mortality, but there have been few attempts at investigating the overall health benefits of multiple drug therapies in older populations. ${ }^{2,3}$

There has also been scientific debate in relation to the implications of multiple drug treatments in the management of chronic disease such as ischaemic

UT Kadam, MSc, MPhil, PhD, MRCGP, senior lecturer in general practice/epidemiology, Arthritis Research UK Primary Care Centre, Keele University, Newcastle-under-Lyme.

Address for correspondence

Dr Umesh T Kadam, Arthritis Research UK Primary Care Centre, Keele University, Newcastle-under-Lyme,

Staffordshire, ST5 5BG. E-mail: u.kadam@cphc.keele.ac.uk

Submitted: 10 June 2010; Editor's response: 27 July 2010; final acceptance: 10 August 2010.

(c) British Journal of General Practice 2011; 61: 128-130.

DOI: 10.3399/bjgp11X556263 heart disease, and it has been postulated that a polypill might be developed to maximise the benefit and adherence. ${ }^{4}$ What is less clear is whether the use of multiple drug regimens in general practice has any beneficial or detrimental effects on overall health at the population level, and specifically in relation to change over a longer-term time period.

\section{METHOD}

This secondary dataset is drawn from a large population-based postal survey, conducted in six general practice populations of individuals aged $\geq 50$ years, at baseline, with a follow-up using the same health questionnaire at 3 years.

For 4506 patients who had consented, individual health survey data were linked to their general practice records, which included drug prescription data over a 5 -year period. The total 5-year time-period for review of clinical data covered the 2 years before the baseline questionnaire survey in 2001 and the 3 years in between baseline and follow-up questionnaires.

\section{Definitions of 3-year change in health}

The Short Form-12 (SF-12) questionnaire summarised physical and psychological health status for each study participant. ${ }^{5}$ Change in health was calculated by subtracting the baseline score from the 3-year followup score, with negative scores indicating relative deterioration and positive scores indicating a relative improvement in health. The change scores were then dichotomised about the mean change for the study populations in respect of physical and psychological scores separately, and, using a $2 \times 2$ table approach, four groups were constructed: (i) controls $d$ physical and psychological health better; (ii) group a - physical health worse/psychological health better; (iii) group $\mathrm{b}-$ psychological health worse/physical health better; and (iv) group c - physical and psychological health worse (Table 1).

\section{Multidrug measures}

Linked prescription data for the study population were obtained from general practice records and these data were based on British National Formulary (BNF) codes. Within each BNF chapter there is a 
hierarchical structure, which details different drugs for the same disease indication or for different classes of drugs within the specific body system. ${ }^{6}$ The definition of multidrug therapy was based on overall counts at the second hierarchy by: 'number of drugs prescribed for an individual including different drugs for the same disease, but not including repeat prescription for the same drug in the same time period'.

\section{Statistical analyses}

Baseline survey measures of health, using the respective study population mean values, were dichotomised SF-12 scores for physical and psychological health. Baseline drug counts in the 2year time period before the survey were dichotomised about the mean and in the 3-year follow-up period counts were categorised into four groups: (i) 1 to 4 prescribed drugs; (ii) 5 to 7 drugs; (iii) 8 to 11 drugs; and (iv) 12 drugs and over. Associations between the four categories of overall drug counts and the three health-change case groups compared to controls were separately assessed using logistic regression methods with $95 \%$ confidence intervals (Cls).

\section{RESULTS}

There was a significant and increasing strength of association between higher drug counts and worse physical and psychological health compared to the lowest counts group (trend $P<0.001$ ). The adjusted figures were: category two, odds ratio (OR) 1.55 $(95 \% \mathrm{Cl}=1.2$ to 2.1$)$; category three, OR 2.25 (95\% $\mathrm{Cl}=1.7$ to 3.1$)$; and category four, OR $2.91(95 \% \mathrm{Cl}$ $=2.0$ to 4.2 ).

There was a significant and increasing strength of association between higher drug counts and worse physical health compared to the lowest counts group (trend $P=0.025)$. The adjusted figures were: category two, OR $1.24(95 \% \mathrm{Cl}=0.97$ to 1.6$)$; category three, OR $1.42(95 \% \mathrm{Cl}=1.1$ to 1.9$)$; and category four, OR $1.64(95 \% \mathrm{Cl}=1.2$ to 2.3$)$ (Table 2).

While the strength of association between higher drug counts and worse psychological health increased (but was weaker), it did not show any significant statistical trend.

\section{DISCUSSION}

\section{Summary of main findings}

There were high levels of multiple drugs routinely prescribed in the older population of individuals aged $\geq 50$ years from general practice, but such high prescribing was not associated with benefit as measured by change in physical and psychological health over a 3-year time period. Therefore, the possible implications that are generated from these results are either that multidrug therapy may be detrimental to health or that there was an increased

\section{How this fits in}

Multiple drugs prescribing in general practice populations is high, but whether this benefits overall health is unknown. Higher levels of drug prescribing were associated with deterioration in physical and combined physical and psychological health. The study highlights the potential need for assessing prescribing in terms of overall health.

prescribing response by clinical practitioners to changing health status.

\section{Strengths and limitations of the study}

In terms of testing a hypothesis, this study was drawn from a large population-based cohort and provides an internal comparison (and 'dose'-relationship) of multidrug counts and its association with health change. The simple drug counts measure does not convey the indication or duration of drug therapies, and whether they were aimed at short-term conditions (for example, antibiotics for infections) or for chronic diseases on an ongoing basis (for example, diabetes or ischaemic heart disease). This approach also does not disentangle the specific drug interactions or adherence issues that might play different roles in influencing health change.,

\section{Comparison with existing literature}

Previous studies indicate that psychological distress is associated with increased comorbidity, ${ }^{9}$ and so is likely to be associated with a higher number of prescribed drug therapies. However, the analyses for the group whose psychological health worsened showed that the prescribing response was relatively weaker than for the other two groups. Clinical practitioners also usually prescribe in response to disease diagnosis or symptoms, as opposed to health change,${ }^{10}$ and this further indicates the need for a prospective investigation into the effect of multiple drug therapy on long-term health change.

\section{Table 1. Health change over 3 years in the population of} individuals aged $\geq 50$ years.

\begin{tabular}{lccc} 
& Number (\%) & Definition & $\begin{array}{c}\text { Mean change } \\
\text { (standard deviation) }\end{array}$ \\
\hline Control group d & $1022(23)$ & $\begin{array}{c}\text { Physically better } \\
\text { Psychologically better }\end{array}$ & $\begin{array}{c}\text { PCS }+4.5(5.39) \\
\text { MCS }+5.4(6.53)\end{array}$ \\
\hline Case group a & $1266(28)$ & $\begin{array}{c}\text { Physically worse } \\
\text { Psychologically better }\end{array}$ & $\begin{array}{c}\text { PCS }-7.8(6.05) \\
\text { MCS }+7.5(7.47)\end{array}$ \\
\hline Case group b & $1378(31)$ & $\begin{array}{c}\text { Physically better } \\
\text { Psychologically worse }\end{array}$ & PCS +6.1 (6.01) \\
& MCS -8.6 (7.16) \\
\hline Case group c & $840(19)$ & $\begin{array}{c}\text { Physically worse } \\
\text { Psychologically worse }\end{array}$ & PCS -8.0 (6.64) \\
& & MCS -8.5 (6.90) \\
\hline
\end{tabular}

${ }^{a}$ Figures in brackets are percentages of the overall study group $(\mathrm{n}=4506)$. ${ }^{\mathrm{b}}$ Based on the Physical Component Summary (PCS) and the Mental Component Summary (MCS) scores from the SF-12 questionnaire. 
Table 2. Associations between multidrug therapy and health change over a 3-year time period.

\begin{tabular}{|c|c|c|c|c|c|c|c|}
\hline \multirow{3}{*}{$\begin{array}{l}\text { Drug } \\
\text { counts }^{\mathrm{a}}\end{array}$} & & & \multirow{3}{*}{$\begin{array}{l}\text { Unadjusted odds } \\
\text { ratio }(95 \% \mathrm{Cl})\end{array}$} & \multicolumn{4}{|c|}{ Adjusted odds ratio (95\% Cl) } \\
\hline & \multicolumn{2}{|c|}{ Health change $^{e}$} & & \multirow{2}{*}{$\begin{array}{c}\text { Age, sex, and } \\
\text { deprivation status }\end{array}$} & \multirow{2}{*}{$\begin{array}{c}\text { Age, sex, } \\
\text { deprivation status, } \\
\text { and baseline physical } \\
\text { and psychological health }\end{array}$} & \multirow{2}{*}{$\begin{array}{c}\text { Age, sex, } \\
\text { deprivation } \\
\text { status, and } \\
\text { baseline drug counts }\end{array}$} & \multirow{2}{*}{$\begin{array}{l}\text { Age, sex, deprivation } \\
\text { status, baseline physical } \\
\text { and psychological } \\
\text { health, and drug counts }\end{array}$} \\
\hline & Better & Worse & & & & & \\
\hline $\begin{array}{l}\text { Category } \\
1^{\text {a }} \text { lowest }\end{array}$ & 317 & 365 & 1.0 & 1.0 & 1.0 & 1.0 & 1.0 \\
\hline Category $2^{\mathrm{b}}$ & 264 & 343 & 1.13 (0.9 to 1.4$)$ & $1.08(0.9$ to 1.3$)$ & 1.22 (0.97 to 1.5$)$ & 1.13 (0.9 to 1.4$)$ & 1.24 (0.97 to 1.6$)$ \\
\hline Category $3^{\mathrm{b}}$ & 258 & 318 & 1.07 (0.9 to 1.3$)$ & 0.99 (0.8 to 1.2$)$ & 1.36 (1.1 to 1.7$)$ & 1.14 (0.9 to 1.5$)$ & 1.42 (1.1 to 1.9$)$ \\
\hline $\begin{array}{l}\text { Category } \\
4^{\mathrm{b}} \text { highest }\end{array}$ & 183 & 240 & 1.13 (0.9 to 1.5$)$ & 0.99 (0.8 to 1.3$)$ & 1.55 (1.2 to 2.1$)$ & 1.19 (0.9 to 1.6$)$ & 1.64 (1.2 to 2.3$)$ \\
\hline $\begin{array}{l}\text { Category } \\
1^{\text {b }} \text { lowest }\end{array}$ & 317 & 361 & 1.0 & 1.0 & 1.0 & 1.0 & 1.0 \\
\hline Category $2^{\circ}$ & 264 & 342 & 1.14 (0.9 to 1.4$)$ & $1.08(0.9$ to 1.4$)$ & 1.06 (0.8 to 1.3$)$ & 1.10 (0.9 to 1.4$)$ & 1.05 (0.8 to 1.3$)$ \\
\hline Category $3^{\circ}$ & 258 & 371 & $1.26(1.0$ to 1.6$)$ & 1.14 (0.9 to 1.4$)$ & 1.16 (0.9 to 1.5$)$ & 1.18 (0.9 to 1.5$)$ & 1.14 (0.9 to 1.5$)$ \\
\hline $\begin{array}{l}\text { Category } \\
4^{\circ} \text { highest }\end{array}$ & 183 & 304 & 1.46 (1.2 to 1.9$)$ & 1.26 (0.98 to 1.6$)$ & 1.47 (1.1 to 2.0 ) & 1.33 (0.98 to 1.8 ) & 1.44 (1.0 to 2.0 ) \\
\hline $\begin{array}{l}\text { Category } \\
1^{\circ} \text { lowest }\end{array}$ & 317 & 199 & 1.0 & 1.0 & 1.0 & 1.0 & 1.0 \\
\hline Category $2^{\mathrm{d}}$ & 264 & 213 & 1.29 (0.99 to 1.7$)$ & 1.19 (0.9 to 1.5$)$ & 1.49 (1.1 to 1.9$)$ & 1.49 (1.1 to 1.9$)$ & 1.55 (1.2 to 2.1$)$ \\
\hline Category $3^{d}$ & 258 & 242 & $1.49(1.2$ to 1.9$)$ & 1.36 (1.1 to 1.8$)$ & 2.09 (1.6 to 2.8$)$ & 2.09 (1.6 to 2.8$)$ & 2.25 (1.7 to 3.1$)$ \\
\hline $\begin{array}{l}\text { Category } \\
4^{d} \text { highest }\end{array}$ & 183 & 186 & $1.62(1.2$ to 2.1$)$ & $1.30(0.98$ to 1.7$)$ & 2.68 (1.9 to 3.7$)$ & 2.68 (1.9 to 3.7$)$ & 2.91 (2.0 to 4.2 ) \\
\hline
\end{tabular}

${ }^{a}$ Drug counts defined as: category 1 (1-4); category 2 (5-7); category 3 (8-11); category 4 (12 and over) in the 3-year interval period. ${ }^{\circ} \mathrm{Cases}$ within this group are people whose physical health was worse but psychological health (SF-12) was better after 3 years. 'Cases within this group are people whose psychological health was worse but physical health (SF-12) was better after 3 years. ${ }^{\circ}$ Cases within this group are people whose physical and psychological health was (SF-12) worse after 3 years. eSame controls for each case group and whose physical and psychological health (SF-12) was better after 3 years.

\section{Implications for clinical practice}

In conclusion, the study shows that multidrug therapy was associated with worse physical health or combined physical and psychological health over a 3-year period. Baseline health or drug prescribing, or sociodemographic characteristics did not explain these results. The importance of the study findings then relates to whether prescribing should be assessed in terms of overall health assessment or whether multipharmacy should be simply viewed as benefiting specific illness or disease management.

\section{Funding body}

The author was funded by an NIHR Fellowship (PAS/PDA/03/07/035); project funding was by the Medical Research Council (UK) and the North Staffordshire Primary Care Research Consortium.

\section{Ethical approval}

Ethical approval was given by the North Staffordshire Local Research Ethics Committee.

\section{Competing interests}

The author has stated that there are none.

\section{Acknowledgements}

An expression of thanks is extended to the patients who took part in the study and the teams who collected the survey and clinical data, and to Peter Croft for his comments on the initial draft of the paper.

\section{Discuss this article}

Contribute and read comments about this article on the Discussion Forum: http://www.rcgp.org.uk/bjgp-discuss

\section{REFERENCES}

1. Junius-Walker U, Theile G, Hummers-Pradier E. Prevalence and predictors of polypharmacy among older primary care patients in Germany. Fam Pract 2007; 24(1): 14-19.

2. Hershman DL, Simonoff PA, Frishman WH, et al. Drug utilization in the old old and how it relates to self-perceived health and all-cause mortality: results from the Bronx Aging Study. J Am Geriatr Soc 1995; 43(4): 356-360.

3. Franic DM, Jiang JZ. Potentially inappropriate drug use and healthrelated quality of life in the elderly. Pharmacotherapy 2006; 26(6): $768-778$.

4. Wald NJ, Law MR. A strategy to reduce cardiovascular disease by more than $80 \%$. BMJ 2003; 326(7404): 1419.

5. Ware J Jr, Kosinski M, Keller SD. A 12-Item Short-Form Health Survey: construction of scales and preliminary tests of reliability and validity. Med Care 1996; 34(3): 220-233.

6. British Medical Association and the Royal Pharmaceutical Society of Great Britain. British National Formulary, No. 58 September 2009. London: BMJ Group and Pharmaceutical Press, 2009.

7. Astrand B, Astrand E, Antonov K, Petersson G. Detection of potential drug interactions - a model for a national pharmacy register. Eur J Clin Pharmacol 2006; 62(9): 749-756.

8. Osterberg L, Blaschke,T. Adherence to medication. N Engl J Med 2005; 353(5): 487-497.

9. Kadam UT, Jordan K, Croft PR. Clinical comorbidity was specific to disease pathology, psychologic distress, and somatic symptom amplification. J Clin Epidemiol 2005; 58(9): 909-917.

10. Pugh MJ, Palmer RF, Parchman ML, et al. Association of suboptimal prescribing and change in lower extremity physical function over time. Gerontology 2007; 53(6): 445-453. 